\title{
Bed Material Agglomeration During Fluidized Bed Combustion
}

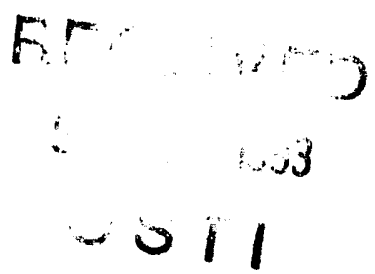

\section{Technical Progress Repont tor the Period}

April 1. 1993 - June 301993

\author{
Robert C. Brown. M. Rober Dawson. and Shawn D. Noble, \\ Iowa State University \\ Ames. IA 50011
}
Work Performed Under Grant
No. DE-FG22-92PC92530

Date Transmitted: July, 1993
Prepared ior: L'.S. Department of Energy
Pushuren Energy Technoiogy Center
Pittsburgh. PA

\section{MASTER}

DISTRIBUTION OF THIS DOCUMENT IS UNLIMITED

\author{
Project Monitor: Wu Lan
}

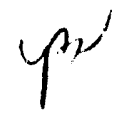

\section{DISCLAIMER}

\footnotetext{
This report was prepared as an account of work sponsored by an agency of the United States Government. Neither the United States Government nor any agency thereof, nor any of their employees, makes any warranty, express or implied, or assumes any legal liability or responsibility for the accuracy, completeness, or usefulness of any information, apparatus, product, or process disclosed, or represents that its use would not infringe privately owned rights. Reference herein to any specific commercial product, process, or service by trade name, trademark, manufacturer, or otherwise does not necessarily constitute or imply its endorsement, recommendation, or favoring by the United States Government or any agency thereof. The views and opinions of authors expressed herein do not necessarily state or reflect those of the United States Government or any agency thereof.
}

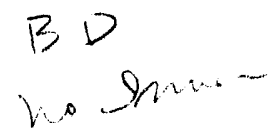




\title{
Bed Material Agglomeration During Fluidized Bed Combustion \\ Technical Progress Report \\ April I, 1993 - June 30, 1993
}

\author{
Robert C. Brown, M. Robert Dawson, and Shawn D. Noble \\ Iowa State University, Ames IA 50011
}

\begin{abstract}
During this quarter laboratory combustion tests were conducted to determine the point at which theoretical air values begin to effect agglomeration of bed particles. Combustion tests were conducted at $75 \%, 90 \%, 100$, and $120 \%$ theoretical air values. A constant value for bed expansion was maintained between experiments by supplementing the air flow difference with nitrogen. The test at $75 \%$ theoretical air resulted in the formation of bed agglomerates within 30 minutes. Agglomeration of bed material was not observed in the other tests.

Additional modifications were made to the combustion laboratory to bring the facility into compliance with OSHA regulations. This work included changes in the electrical wiring and relocation of equipment. Also during this quarter, an electronic filter used to filter signal noise was redesigned to improve measurements of pressure fluctuations within the bed. These measurements provide a mechanism to determine the kinetics of agglomerate growth.

A survey of agglomeration and deposit formation in industrial fluidized bed boilers indicate that several facilities are experiencing some form of bed material agglomeration. Deposit formation was reported at nine sites with these deposits being found most commonly at coal feed locations and in cyclones. Deposit and agglomerate samples have been received from four units.

The analyses of material from one of these facilities in nearing completion. At this location, a tluidized bed burner is used to warm coke as part of a process to refine bitumen. Deposit formation in the cyclones was reponted to be a major problem. Deposits were also reported to have occurred in the dense phase of the bed. This burner operates at less than $100 \%$ theoretical air so the coke can be heated without combusting the coke.

Our analyses of the cyclone deposits indicate they are primarily composed of an ironaluminosilicate material. The bulk of the deposit is about $30 \mathrm{wt} \% \mathrm{SiO}_{2}, 18 \mathrm{wt} \% \mathrm{Al}_{2} \mathrm{O}_{3}$, and 30 to $33 \mathrm{wt} \% \mathrm{Fe}_{2} \mathrm{O}_{3}$. Titanium is also present between 3 and $4 \mathrm{wt} \%$. All the iron in the deposit is now in the $\mathrm{Fe}+3$ state. but there is evidence that at the time of deposit formation it was in the $\mathrm{Fe}+2$ state. The atomic structure of the bulk of the deposit is that of the spinel mineral maghemite. In nature, this is a rare mineral which forms by the oxidation of the mineral magnetite. Magnetite contains iron in both the +2 and +3 states and can incorporate titanium into its structure at low oxygen fugacities. The relatively high titanium content of the deposit suggests that it may have originally been magnetite (formed at a low oxygen fugacity), but was later oxidized to maghemite under higher oxygen fugacities. We have hypothesized that the cause of deposit formation was most likely interaction of iron, as a flux (in a reduced form), with aluminosilicate materials (clays). The iron probably originated as pyrite or iron sulfides in the feed. It also appears the quench water plays a role in enhancing the deposit formation in the cyclones. We have hypothesized that the high iron content of solids in the sour quench water probably did not play a role in deposit formation; although, the high water vapor pressure may have had an effect on the viscosity of the material. The alkalic elements, $\mathrm{Na}$ and $\mathrm{K}$, probably played only a minor role in deposit formation.
\end{abstract}




\section{Ecci Material Agglomeration During Fluidized Bed Combustion \\ Robert C. Brown. M. Rubert Dawson, and Shawn D. Noble}

\section{Objective}

The purpose of this project is to determine the physical and chemical reactions which lead to the undesired agglomeration of bed material during fluidized bed combustion and to relate these reactions to specific causes.

\section{Progress}

\section{Laboratory Combustion Tests.}

Laboratory experiments were conducted this past quarter to determine the effect of the combustior air equivalence ratio on the agglomeration of bed material. The combustion tests were run for two and a half to three hours unless early termination was necessary due to the formation of agglomerates.

These experiments were all conducted using the same bed expansion as $120 \%$ theoretical air. This was accomplished by replacing the air flow difference between $120 \%$ and the equivalence ratio with an inert gas, nitrogen. The nitrogen was introduced into the plenum to ensure complete mixing with the combustion air. In all of the experiments, the bed was preheated with natural gas and gradually switched over to coal while trying to maintain $120 \%$ theoretical air. Once the switch over was achieved, the operating conditions were changed to reflect the equivalence ratio being tested in the experiment. Table 1 shows the equivalence ratio used in each combustion test and the effect on the bed.

Table 1. Test number and equivalence ratios.

\begin{tabular}{ccc} 
EXPERIMENT & EQUIVALENCERATIO & RESULT \\
\cline { 1 - 2 } Run 1 & 1.20 & no agglomeration \\
Run 2 & 1.20 & no agglomeration \\
Run 3 & 1.00 & no agglomeration \\
Run 4 & 0.75 & agglomeration \\
Run 5 & 0.90 & no agglomeration \\
Run 6 & 0.75 & agglomeration
\end{tabular}

Run 1 was conducted at 120\% of theoretical air. The bed consisted of 5.8 liters of $30 \times 40$ U.S. mesh sand. During this test, the bed temperature did not exceed $1500^{\circ} \mathrm{F}$. The reason for the low temperature was determined to be due to the sand particle size used for the bed. Due to the high heat transfer rates out of the bed using $30 \times 40$ U.S. mesh sand, the particle size used for 
the bed was switched to $20 \times 30$ U.S. mesh for Run 2. This allowed the bed temperature to reach in excess of $1500^{\circ} \mathrm{F}$. Figures $1-4$ show the pressure, temperature, and gas analyses for Run 2.

An equivalence ratio of 1.00 was used for Run 3 . At this equivalence ratio, the bed temperature increased rapidly to $1700^{\circ} \mathrm{F}$. To protect the equipment, the experiment was terminated early. No agglomerates were formed.

Test 4 was run at an equivalence ratio of 0.75 . In this test, the bed temperature went well in excess of $1700^{\circ} \mathrm{F}$ in under 30 minutes, and the experiment was terminated. Agglomerates of bed particles were formed and are being analyzed. The following observations were made: During combustion, the bed was a dim orange color and not brightly orange as in previous experiments. Just before terminating the experiment, particles of approximately $4 \mathrm{~mm}$ in size were noticed in the bed; some were brighter than the bed, others were dark in color. After termination, the bright particles grew in size and number. Attempts to drain the bed through the drain port were unsuccessful. The combustor had to be disassembled. Upon disassembly, agglomerates were found in the bed. Figures 5-8 are graphs of the data collected for this experiment.

Run 5 was conducted at an equivalence ratio of 0.90 . This equivalence ratio did not yield any agglomeration. Run 6 was performed with an equivalence ratio of 0.75 to determine if the bed temperature of run 4 could be controlled for more than 30 minutes and, if so, when catastrophic failure would occur. It was found that the temperature could be controlled by reducing the coal feed and gas feeds proportionately so as to maintain a constant equivalence ratio. Problems with the electronic filter and exhaust gas sample line started to appear during the experiment. The electronic filter had partial failure and the exhaust sample line began to plug. Because of these problems, the data taken was corrupted in the form of spikes appearing in the data. However, it was noted that at a bed temperature of approximately $1580^{\circ} \mathrm{F}$, the combustion bed appeared black in color, not orange as expected. At this point, the test was terminated and agglomerates were found in the combustor.

\section{Combustor Modifications}

During this quarter additional modifications were made to the combustion laboratory to bring the facility into compliance with OSHA regulations. This work included changes in the electrical wiring and relocation of equipment.

Modifications were made in the electronic filter designed to eliminate noise in the bed pressure transducer signal. The original design was a third order low pass filter with a resistive value of $122 \mathrm{k} \Omega$ and capacitance of $10 \mu \mathrm{F}$. When tested, this design gave too long of a rise time. The resistive value was then decreased to $102.2 \mathrm{k} \Omega$ and the capacitance to $10 \mu \mathrm{F}$. This setup gave an acceptable rise time of approximately 10 seconds. It was decided to use this filter while on the breadboard, which would allow changes in the resistive and capacitance values. During one experimental run, the electronic filter showed signs of failure and did actually fail during the next experiment. When this occurred. the filter was rebuilt as a fourth order filter with a resistive value of $276 \mathrm{k} \Omega$ and a capacitance of $10 \mu \mathrm{F}$. These new values of resistance and capacitance were the result of experience with the previous filter and use of a signal generator and osciiloscope. The rebuilt filter was then soldered to a circuit card and installed. 


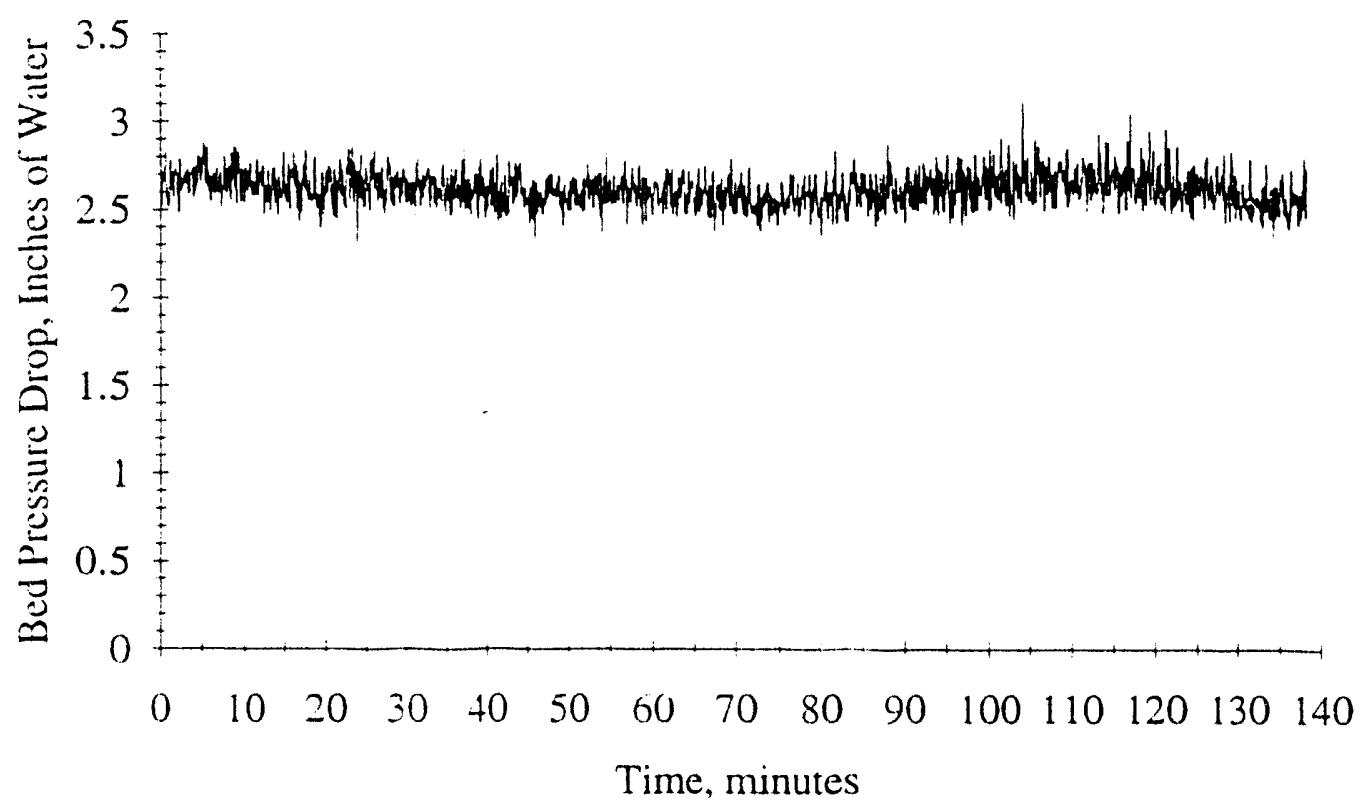

Figure 1. Bed pressure over time for a combustion test at $120 \%$ theoretical air.

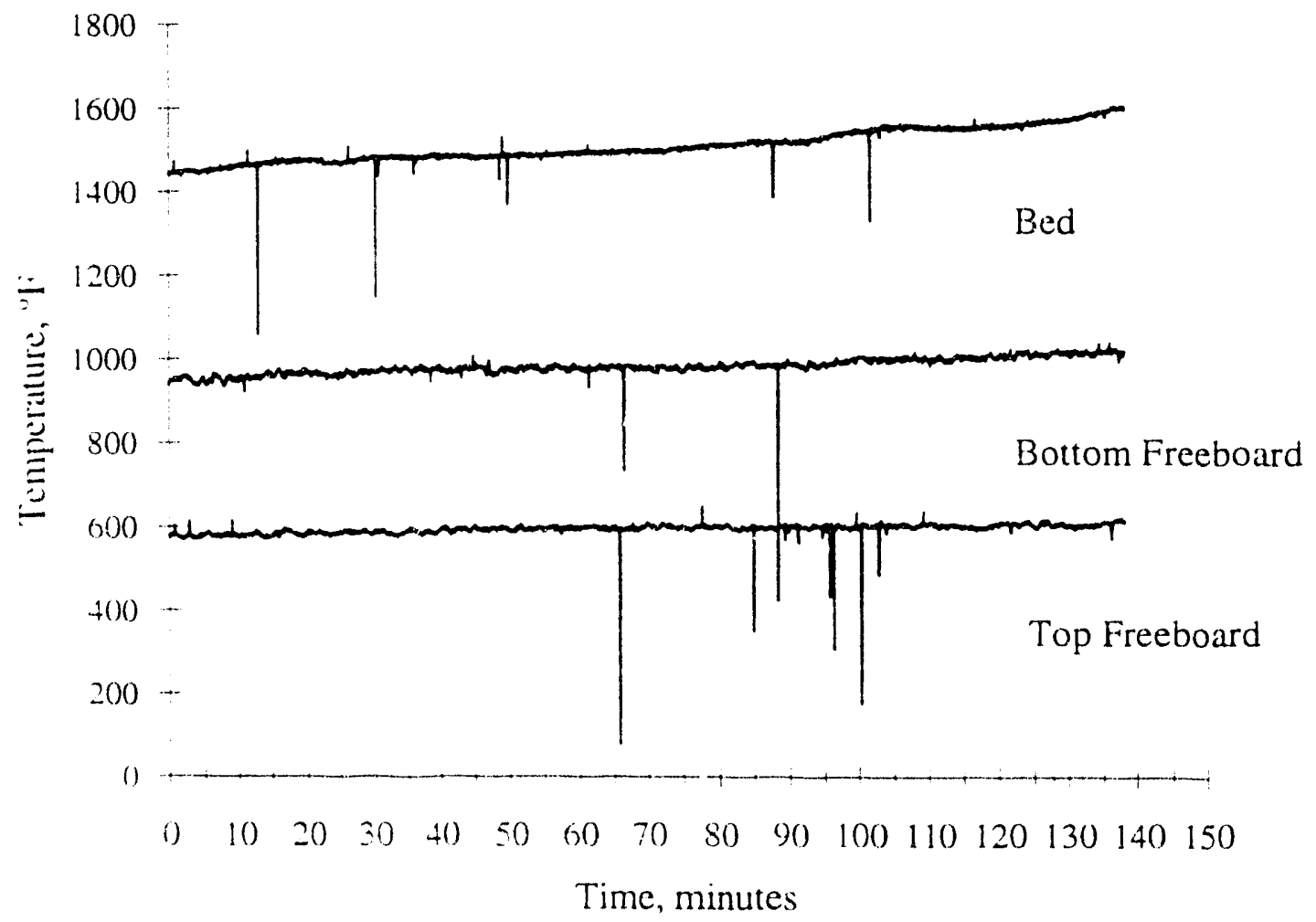

Figure 2. Combustor temperatures over time for a combustion test at $120 \%$ theoretical air. 


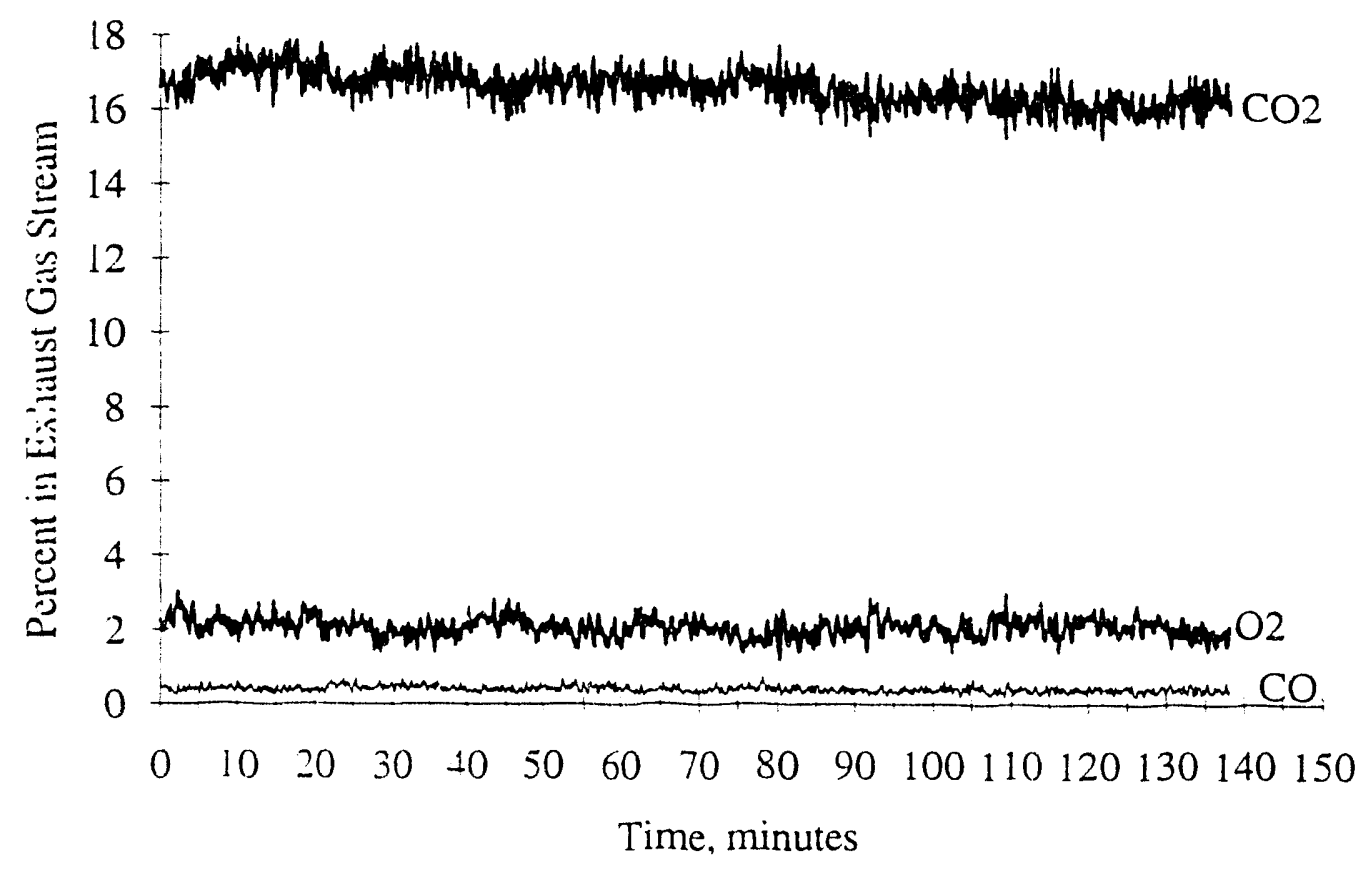

Figure 3. $\mathrm{CO}_{2}, \mathrm{O}_{2}$, and $\mathrm{CO}$ over time for a combustion test at $120 \%$ theoretical air.

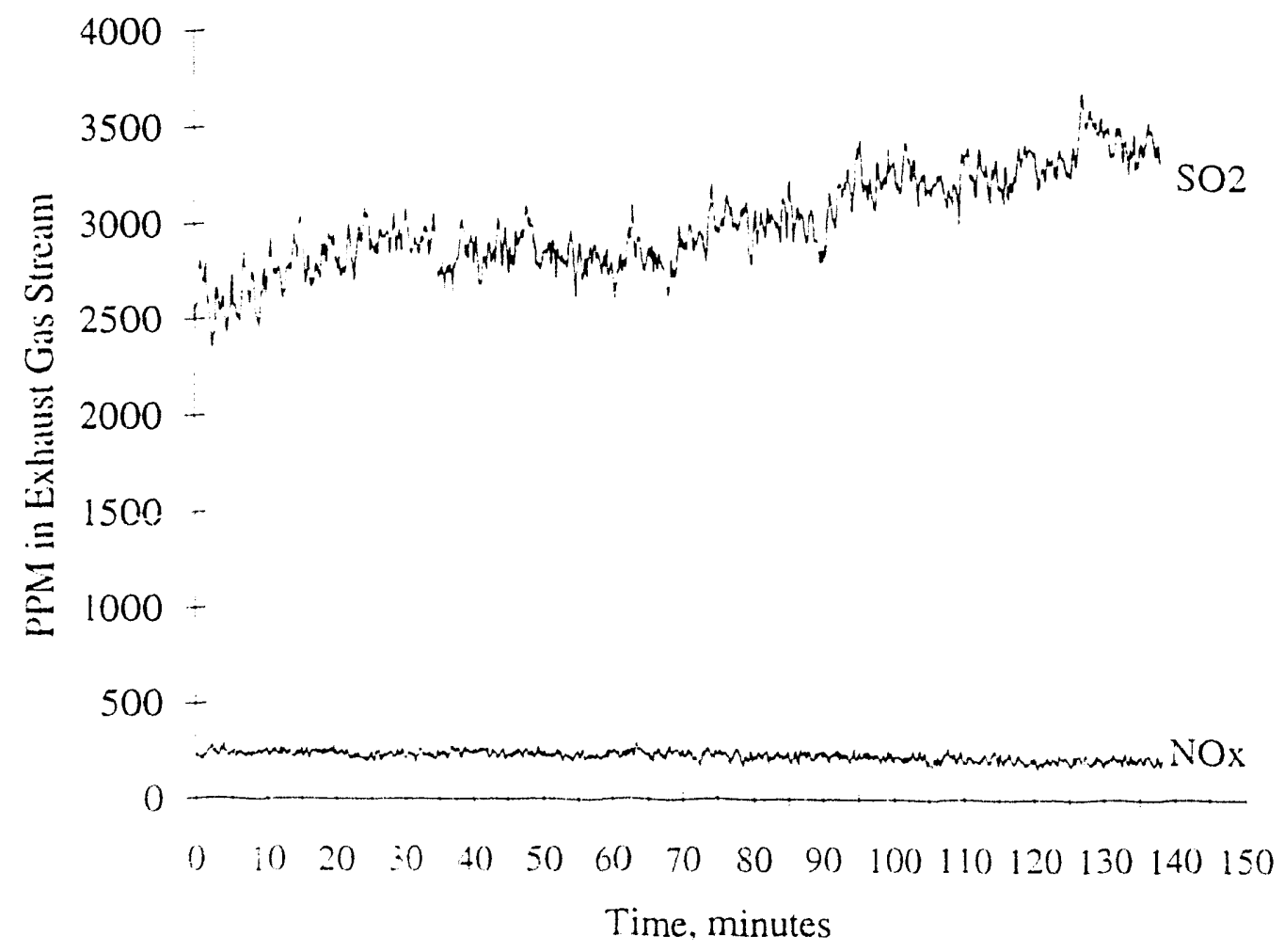

Figure 4. $\mathrm{SO}_{2}$ and $\mathrm{NO}_{\mathrm{X}}$ over time for a combustion test at $120 \%$ theoretical air. 


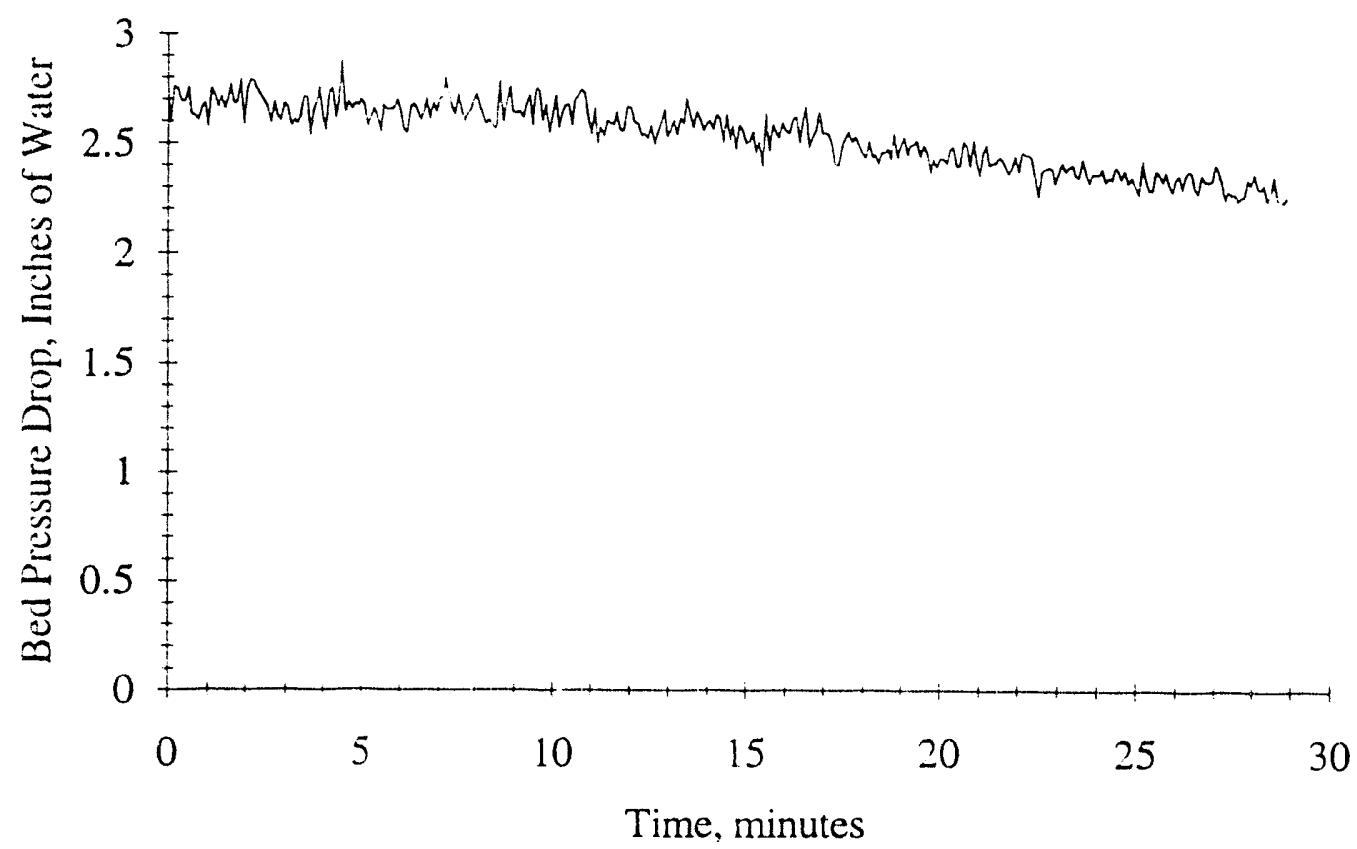

Figure 5. Bed pressure over time for a combustion test at $75 \%$ theoretical air.

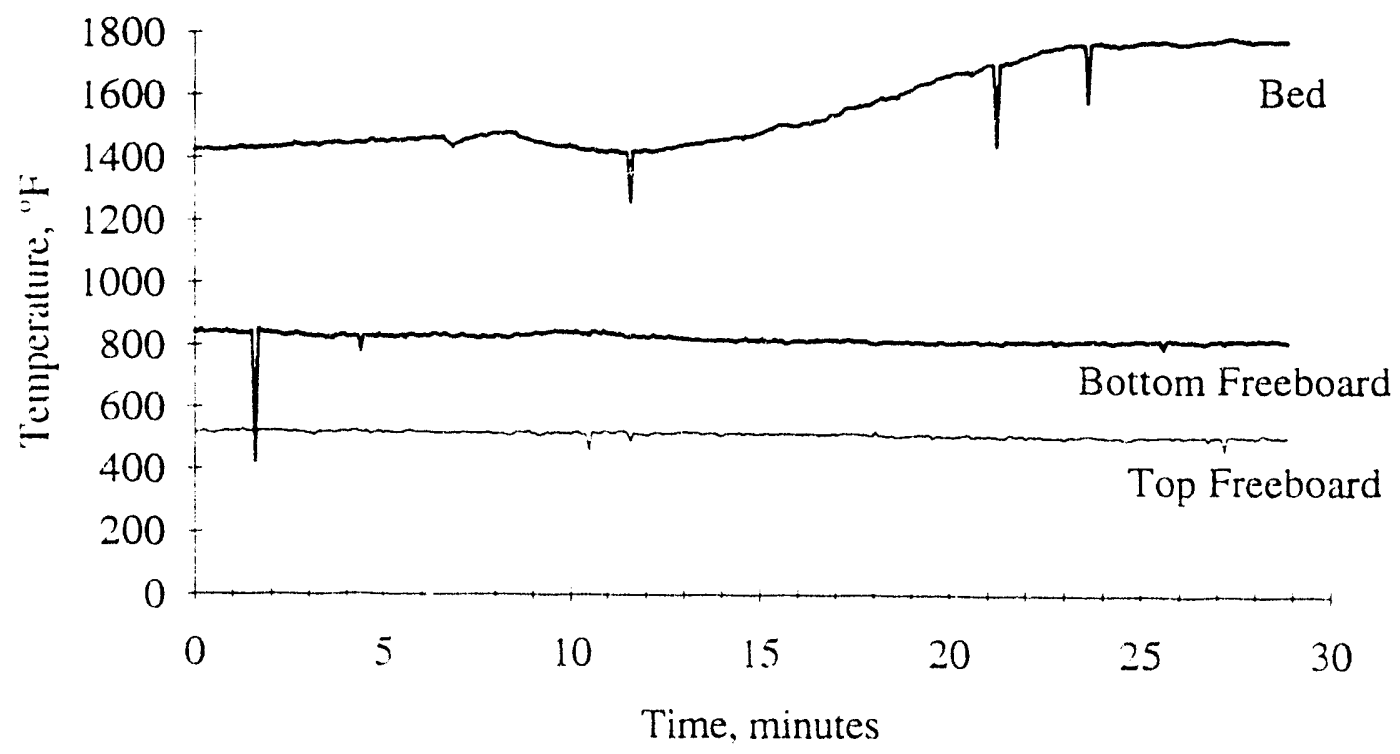

Figure 6. Combustor temperatures over time for a combustion test at $75 \%$ theoretical air. 


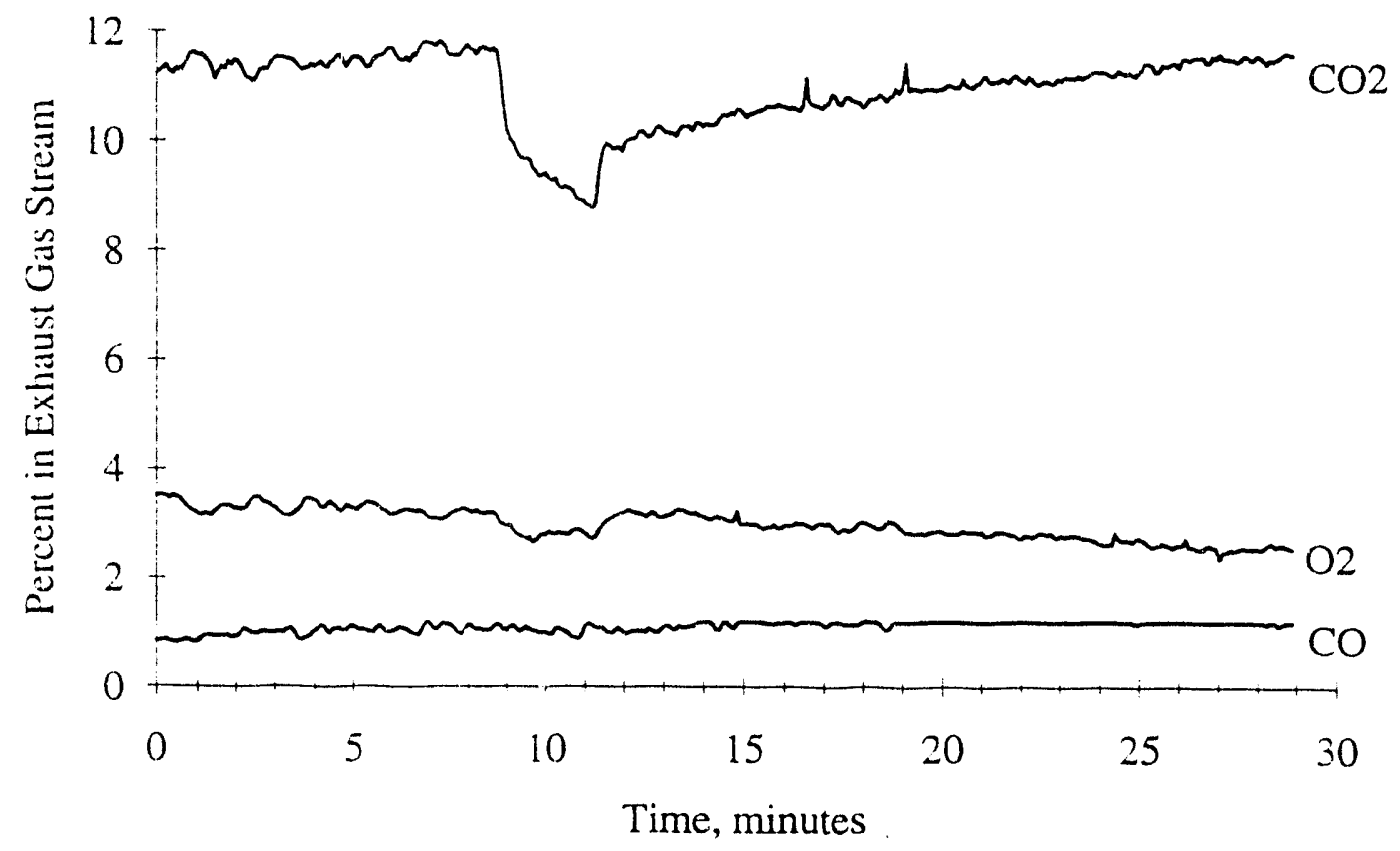

Figure 7. $\mathrm{CO}_{2}, \mathrm{O}_{2}$, and $\mathrm{CO}$ over time for a combustion test at $75 \%$ theoretical air.

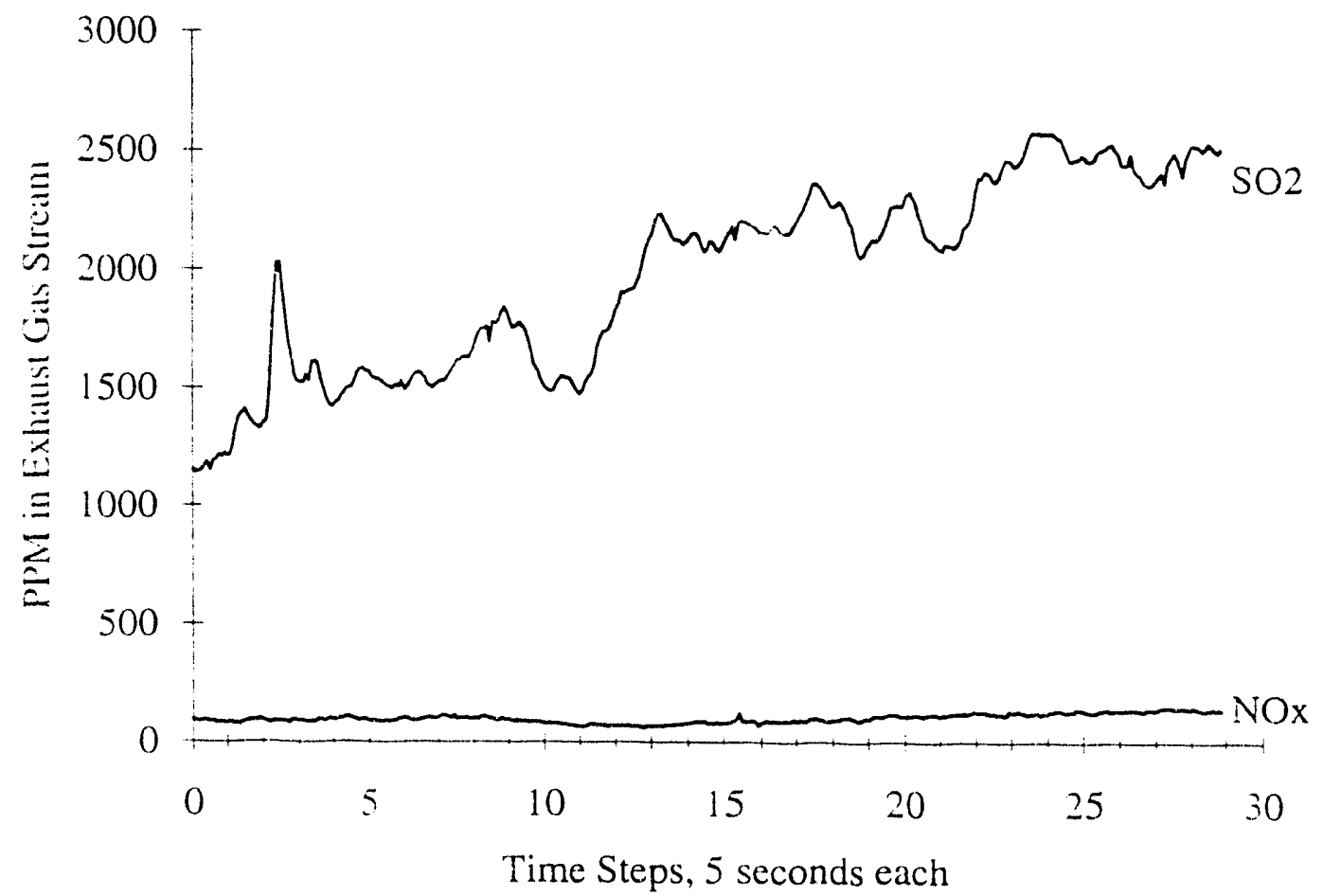

Figure 8. $\mathrm{SO}_{2}$ and $\mathrm{NO}_{\mathrm{X}}$ over time for a combustion test at $75 \%$ theoretical air. 


\section{Industrial Survey}

A survey of agglomerate and deposit formation in industrial fluidized bed boilers indicates that several facilities are experiencing some form of bed material agglomeration. Deposit formation was reported at nine sites with these deposits being found most commonly at coal feed locations and in cyclones. Deposit and agglomerate samples have been received from four units.

The analyses of material from one of these facilities is nearing completion. At this location, a fluidized bed burner is used to warm coke as part of a process to refine bitumen. Deposit tormation in the cyclones were reported to be a major problem. Deposits were also reported to have occurred in the dense phase of the bed. This burner operates at less than $100 \%$ theoretical air so the coke can be heated without combustion.

Methods of Analyses: Bulk chemical compositions (major, minor, and trace elements) of the rim and core of the cyclone deposit were determined by $x$-ray fluorescence (XRF) using a Siemens wavelength-dispersive XRF spectrometer and inductively coupled plasma atomic emission spectroscopy (ICP-AES). The accuracy of all analytical techniques was monitored using standards, run as unknowns, and the analyzed values were compared to published values.

Polished sections of the cyclone deposits were made for optical and scanning electron microscopy. Polarized-light microscopy was performed using a Zeiss research microscope. Photographic "maps", made using retlected light, were also used for scanning electron microscopy (SEM). Analyses for O. $\mathrm{Na}, \mathrm{Mg}, \mathrm{Si}, \mathrm{Al}, \mathrm{S}, \mathrm{Cl}, \mathrm{K}, \mathrm{Ca}, \mathrm{Ti}, \mathrm{V}, \mathrm{Mn}, \mathrm{Fe}$, and $\mathrm{Cu}$ in individual particles and layers within the deposits were obtained using a JEOL JSM-840A SEM equipped with a Kevex Delta V energy-dispersive microanalyzer.

$X$-ray diffraction analyses were performed using a Siemens X-ray diffractometer with K- $\alpha$ copper radiation. Standard titrations were performed to determine the relative proportions of iron $(+2)$ to iron $(+3)$ in both the red and black portions of the cyclone deposit.

Results: The bulk chemical compositions of the "red rim" and the "black core" are presented in Table 2. Microanalyses of deposit lavers and particles within the deposit are given in Table 3. The salient points of the analyses:

- The deposit consists of thin layers primarily composed of three phases. Average chemical compositions of these three phases are given in Table 2. The principal phase is an iron aluminosilicate material (Table 2 and Table 3, analyses 1-5). The minor phases are rounded to angular sulfide particles embedded in the deposit and a "dusting" of sulfide particies between the layers in the deposit (Table 3, analyses 8-11).

- The chemical composition of the rim (red) is identical to the core (black) (see Table 2 and Table 3).

- Titration for Fe+2 indicates all iron in the deposit is now Fe+3. This conclusion is also supported by SEM microanalyses of oxygen, and the red color of the rim material.

- X-ray diffraction indicates a structural difference between the core and the rim, with the core exhibiting a "glassy" structure. X-ray diffraction patterns of the core and rim are different, with the core diffraction pattern showing a strong decrease in peak intensity. This is due to 
the loss of atomic structure of the material as it changes to an amorphous or "glassy" form. The red rim appears to have the mineralogic structure of mag lemite. This mineral has an inverse spinel structure, and in nature, has a composition of $\mathrm{Fe}_{2} \mathrm{O}_{3}$, with iron in the +3 or oxidized state. In nature, this mineral is an oxidation product of magnetite, which has iron in both the +2 and +3 state. The formation and stability of these minerals are strongly dependent on oxygen fugacity and temperature.

Table 2. Bulk chemical composition (major, minor, and trace elements) of the core and rim of the cyclone samples.

\begin{tabular}{lcc} 
& Rim (Red) & Core (Black) \\
\cline { 2 - 3 } $\mathrm{SiO}_{2}$ & 30.22 & 29.28 \\
$\mathrm{Al}_{2} \mathrm{O}_{3}$ & 18.04 & 17.20 \\
$\mathrm{Fe}_{2} \mathrm{O}_{3}$ & 32.84 & 30.88 \\
$\mathrm{SO}_{3}$ & 0.68 & 0.43 \\
$\mathrm{CaO}$ & 1.11 & 1.10 \\
$\mathrm{MgO}$ & 0.97 & 0.97 \\
$\mathrm{P}_{2} \mathrm{O}_{5}$ & 0.24 & 0.21 \\
$\mathrm{~K}_{2} \mathrm{O}$ & 1.14 & 1.08 \\
$\mathrm{Na}_{2} \mathrm{O}$ & 0.84 & 0.78 \\
$\mathrm{TiO}$ & 3.40 & 3.06 \\
$\mathrm{MnO}$ & 0.84 & 0.64 \\
$\mathrm{SrO}$ & 0.05 & 0.04 \\
$\mathrm{BaO}$ & 0.10 & 0.10 \\
$\mathrm{LOI}$ & 8.78 & 13.73 \\
$\mathrm{Total}$ & 99.25 & 99.50 \\
$\mathrm{Co}(\mathrm{ppm})$ & 371 & 391 \\
$\mathrm{Cu}$ & 226 & 213 \\
$\mathrm{Ni}$ & 992 & 1040 \\
$\mathrm{~Pb}$ & 350 & 350 \\
$\mathrm{Zn}$ & 158 & 202 \\
\hline
\end{tabular}

Discussion: Bulk chemical and SEM microanalyses indicate that the cyclone deposits are primarily an iron-aluminosilicate material. The bulk of the deposit is about $30 \mathrm{wt} \% \mathrm{SiO}_{2}, 18 \mathrm{wt} \%$ $\mathrm{Al}_{2} \mathrm{O}_{3}$, and 30 to $33 \mathrm{wt} \% \mathrm{Fe}_{2} \mathrm{O}_{3}$. Titanium is also present between 3 and 4 weight percent.

The most likely cause of formation of the deposits is the interaction of an iron compound with aluminosilicates. The iron probably originated as pyrite or iron sulfides in the feed. The aluminosilicates were probably present as clays in the feed. Iron in the form of $\mathrm{FeS}_{2}$ is a strong fluxing agent in a neutral or mildly reducing atmosphere. In oxidizing zones, $\mathrm{FeS}_{2}$ will typically produce $\mathrm{SO}_{2}$ and form ferric oxide $\left(\mathrm{Fe}_{2} \mathrm{O}_{3}\right)$ at temperatures near $520^{\circ} \mathrm{C}$. In reducing zones, pyrite $\left(\mathrm{FeS}_{2}\right)$ forms a partial melt of ferrous sulfide $(\mathrm{FeS})$ beginning at about $280^{\circ} \mathrm{C}$ and continuing to about $600^{\circ} \mathrm{C}$. Iron oxides may also be reduced to the ferrous state at $540{ }^{\circ} \mathrm{C}$. At lower temperatures, FeS may react with aluminosilicates to form a relatively low-melting ferrous 
metasilicate or form a ferrous orthosilicate. The low melting point of these materials may also enhance formation of inolten spheres of ash particles.

Even though the iron in the deposit is now in the Fe+3 state, there is evidence that at the time of deposit formation it was in the Fe+2 state. The atomic structure of the bulk of the deposit is that of the spinel mineral maghemite $\left(\gamma-\mathrm{Fe}_{2} \mathrm{O}_{3}\right)$. In nature, this is a rare mineral which forms by the oxidation of the spinel mineral magnetite $\left(\mathrm{Fe}_{3} \mathrm{O}_{4}\right.$, or $\left.\mathrm{Fe}_{2} \mathrm{O}_{3}+\mathrm{FeO}\right)$. Formation of the spinel structure requires the presence of iron in the +2 state. The iron was probably oxidized to the +3 state after deposit formation, resulting in the transformation to the maghemite structure. The original presence of iron in the +2 state is also supported by the relatively high titanium content of the deposit. The relatively high titanium content of the deposit suggests that it may have originally been magnetite (formed at a low oxygen fugacity), but was later oxidized to maghemite under higher oxygen fugacities.

The high iron content of the sour quench water (analyses 21 , Table 3 ) may suggest a role in the deposit formation; however, we don't believe the quench w/ater played a role in the initial fluxing reactions. The quench water solids are very high in sulfur, which would have combined with the iron aluminosilicates; howeve the deposit samples are very low in sulfur (bulk analyses show less than one weight percent). In the SEM analyses of the deposit, sulfur is present in individual particles which have not reacted with the deposit. It is possible some of these particles came from the quench water. Although the quench water was not responsible for the initial fluxing of the aluminosilicates, the high water vapor pressure may have had a effect on the viscosity of the material.

The material which formed the deposit appears to have been fluid while it was in the cyclones. This is indicated by the fine layering of the deposit and by the "impact" features and voids near included particles.

The alkalic elements $\mathrm{Na}$ and $\mathrm{K}$ probably played a minor role in deposit formation. Sodıum concentrations in the deposit are less than one weight percent and potassium is about one weight percent. These elements may be present in the deposit as feldspar minerals incorporated from the feed. In this form they will be unreactive. If present in the vapor phase they may act as a fluxing compound; however, there was no indication of sodium sulfate formation, suggesting very little vapor phase sodium.

\section{Future Work}

Work for the next quarter includes continuation of theoretical air tests. Analyses to determine the mineralogic reactions in the samples from the first set of tests will be completed during the next quarter. Also, analyses of deposits from three additional industrial fluidized bed combustors will be completed. 


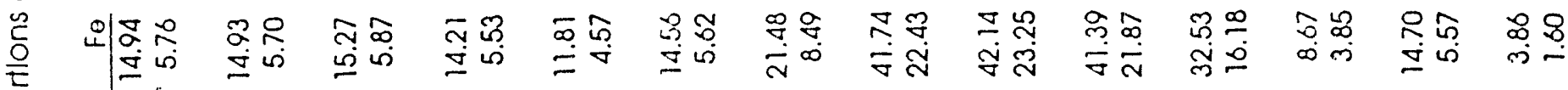

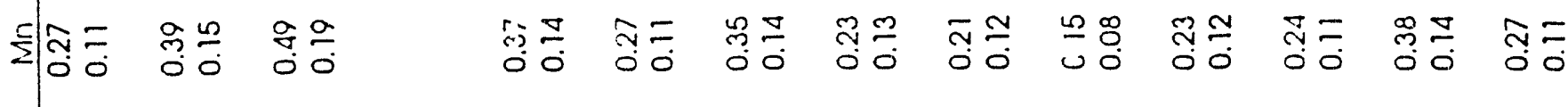
$>$ ᄀ芯

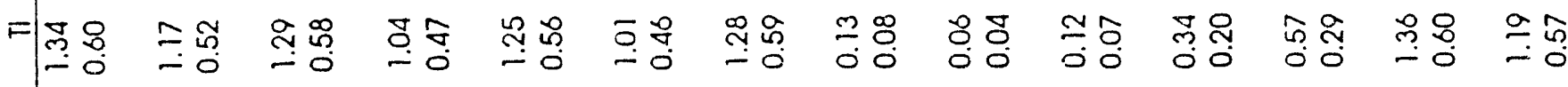
பு

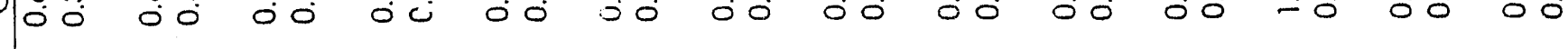

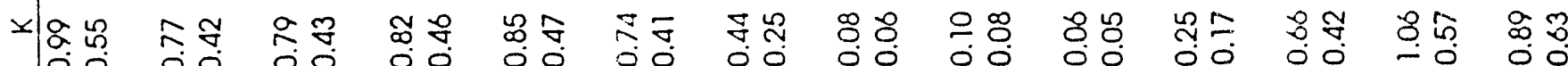

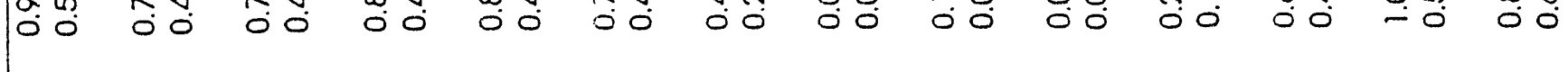

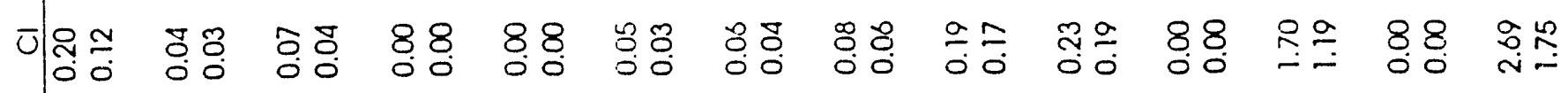

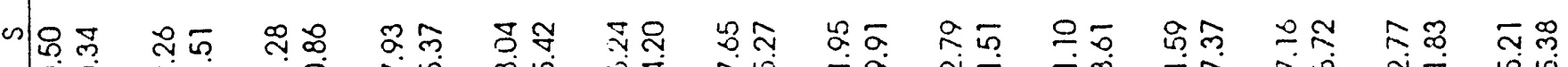
वं त-

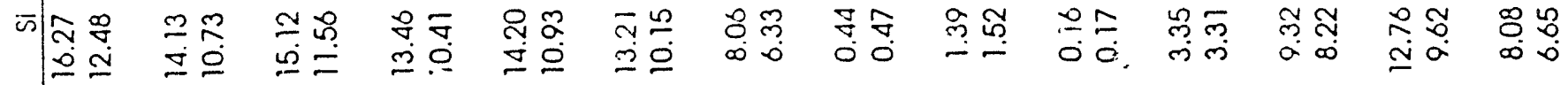
ব중

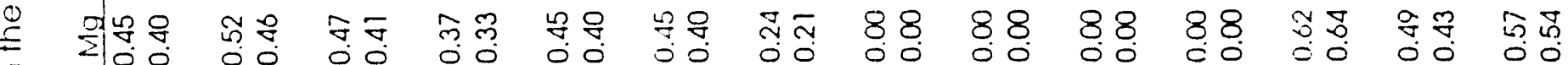
$\subseteq$

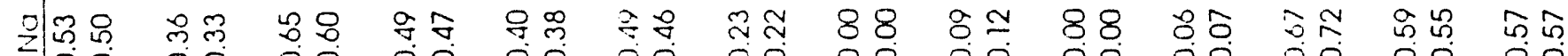

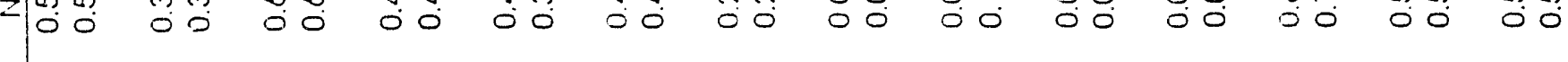

프 유

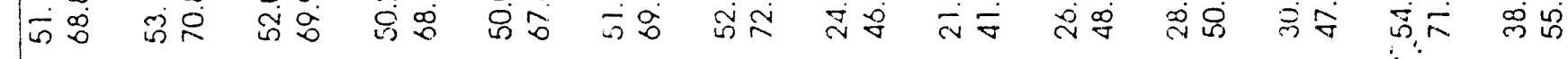

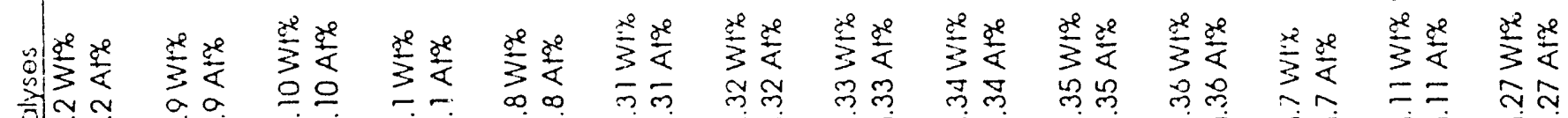
휚 ণ

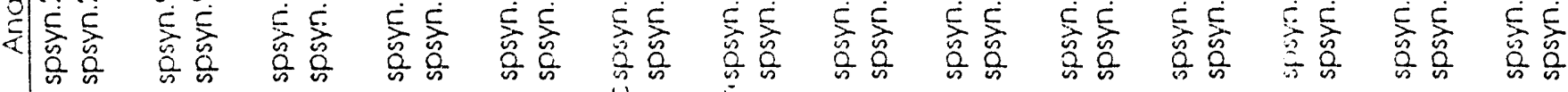


(3)

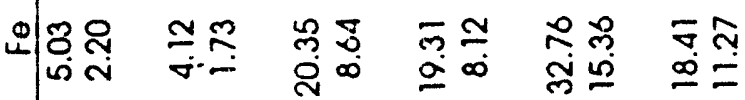

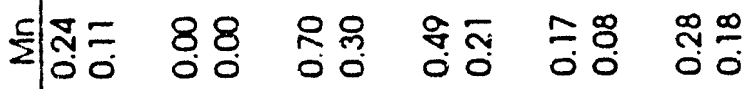

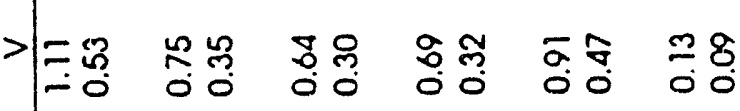

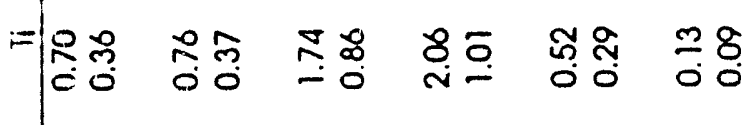

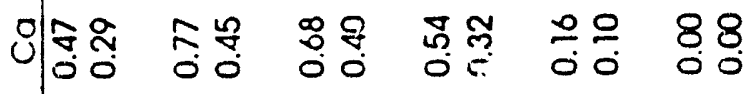

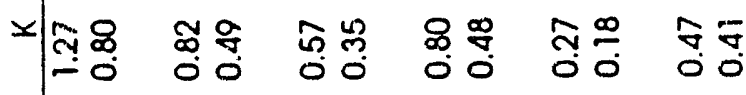

ర뀽

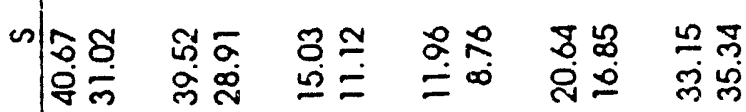

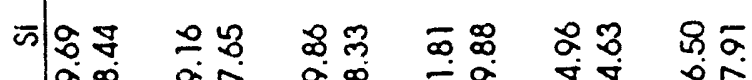

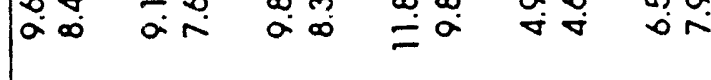

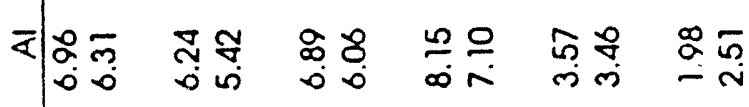

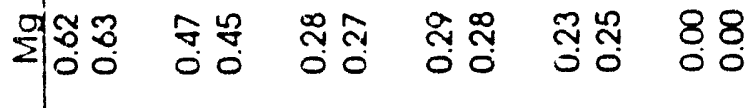

₹

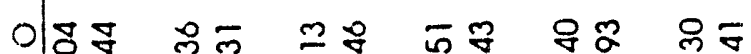
ले लं

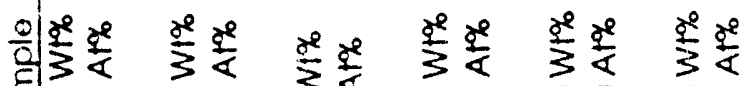

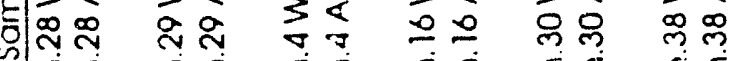

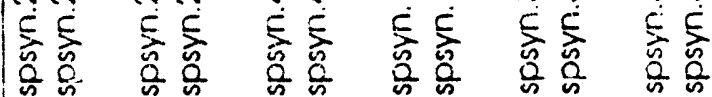

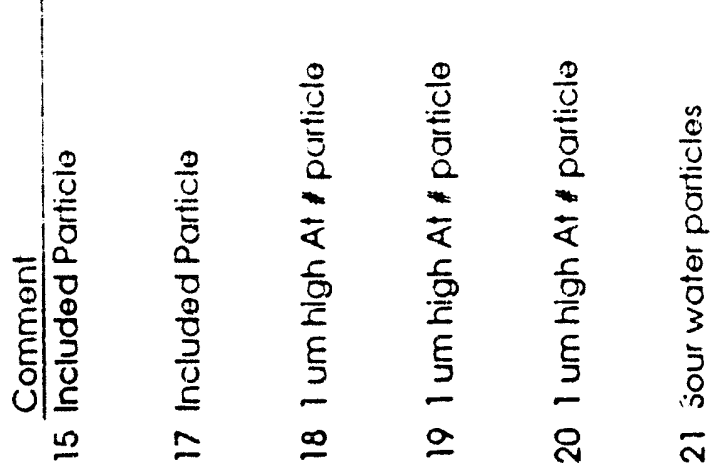



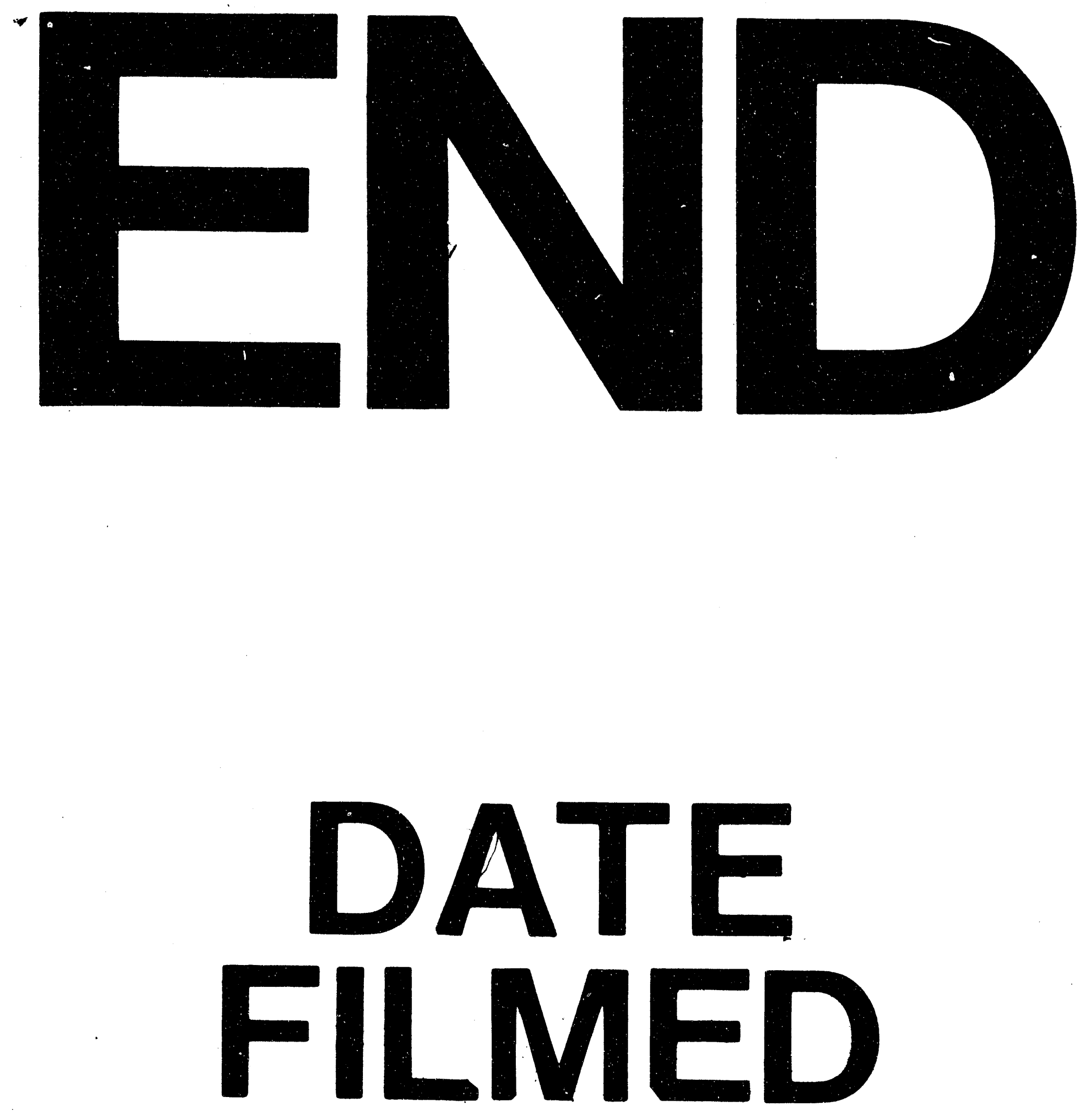

1

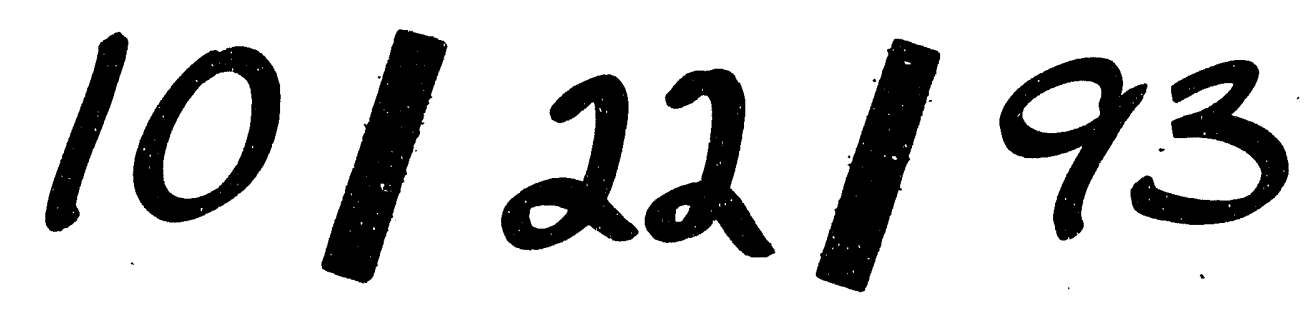


